\title{
Threshold Approaches to Architectural Design Studio
}

\author{
Ebru Alakavuk ${ }^{1, *}$ \\ ${ }^{1}$ Yasar University, Üniversite Street No:37-39 Ağaçlıyol Bornova, İzmir, Turkey
}

\begin{abstract}
Threshold is a popular design theory in architecture that can be defined in many ways. One definition is "a barrier space that is located for separating the volumes". This is "dictionary definition" of the threshold, but in fact this term can has various meanings according to the different perspectives. The threshold can be physical, psychological, emotional, social, economic, etc. definitions. There are many ways of expressing threshold in to architectural design considering the terms mentioned above. In this paper different ways of expressing "threshold" term in to the architectural design is discussed. For this purpose third year architecture design studio is taken as a case study. The student projects by the ways of defining and expressing the threshold term in to design is taken in consideration. The aim of this paper to put forward the integration of various meanings of threshold in to the architectural design by the case studies that are obtained from the architectural design studio.
\end{abstract}

Keywords: Architectural Design, Threshold, Architectural Education

\section{Introduction}

Threshold is; "the floor of an entrance to a building or room" according to the Cambridge Dictionary. In Longman Dictionary the definitions for threshold are; "the level at which something starts to happen or have an effect" and "at the beginning of a new and important event or development. This is the physical definition of threshold that in this definition threshold is taken account just like a separation or connection element located between different spaces. But as it is known threshold does not have only this meaning. It also has physical, psychological, emotional, social, economical, etc. meanings. The problem is how to apply different meanings of threshold on architectural design and also putting forward the importance of designing with threshold.

Walter Benjamin notes: The threshold must be carefully distinguished from the boundary. A Schwelle "threshold" is a zone. Transformation, passage, wave action are in the word Schwellen swell, and etymology ought not to overlook these senses. On the other hand, it is necessary to keep in mind the immediate tectonic and ceremonial context which has brought the word to its current meaning [3]. Till Boettger notes that thresholds are spatial conditions that create openings in boundaries allowing for movement and transition in space [4].

* Corresponding author: ebru.alakavuk@yasar.edu.tr 
The transactions between the two distinct spatial environments include movement of people through thresholds such as doors, verandahs, colonnades, porches, triumphal arches, terraces, marquees, stairways, patios, loggias, and stoops. Besides the passage of people across a physical boundary, mediation across environmental, acoustic, and visual boundaries includes flow of air, light, sound, and odor through thresholds such as doors, windows, louvers, and screens. While allowing transition, mediation, and passage through boundaries, thresholds are associated with specific symbolic meanings, rituals, and sociocultural behavioral codes [5].

A threshold concept is fundamentally transformative: it may be considered 'akin to a portal, opening up a new and previously inaccessible way of thinking about something ... it represents a transformed way of understanding, or interpreting, or viewing . . . without which the learner cannot progress' [6].

Threshold: what is it? Catherine Dee in her book 'Form and Fabric in Architecture' regards it as a spatial component which provides for integrated, subtle and complex transitions. The threshold is the space that links spaces, mediums or objects [7].

\section{Threshold approaches to architectural design studio}

As mentioned above threshold is not only the entrance of the buildings. It has different meanings more than that. Expressing the meaning of threshold in to architectural design is not an easy thing.

In this paper meanings, influence and effects of threshold on design is discussed in the third year architecture design studio course. Methods that are used in this study are literature review, evaluation of design with threshold and observing the architectural design process. Firstly, students are asked to question the meaning of the threshold. And then they applied the threshold on their projects. The students are asked to create a threshold in their design. The meaning and ways for applying threshold in their design are up to students. Every student takes the term in different perspective. Some take physical while others take psychological threshold. The objective of this paper is putting forward the effect of understanding of threshold on design process. For this purpose students design their projects with threshold and reflect this term on their design with the meaning they want. Some of them thought threshold as a separator that divides spaces in to zones while some thought threshold as an intersection, gathering point. By naming and designing road, walkways as threshold the students designed a physical threshold. They divide the architectural design in zones like public, semi public and private areas with the physical threshold as roads. With these roads the boundaries of the zones are defined in a natural way. There is no need to put any other architectural element for emphasizing the boundaries. On the other hand some students thought threshold as a connection element for different functions. They combine old places or areas with new ones by the help of threshold. Or they combine underwater places with upper ones by using thresholds.

Taking account threshold in design process, affects the main design idea and maybe sometimes concept. Evaluation the importance of threshold in architectural design is the significance of this paper. Because understanding the aim of threshold in designs can let us understand the architectural design correctly and easily. Every perspective towards and also including threshold can have different point of view.

In one of the student project threshold creates the connectivity between nature and the built environment. Threshold guided the design of the project and revealed structures with two separate functions. Threshold provides fresh air and access in between spaces. And this Project named as sense of time scale, (Fig 1). 


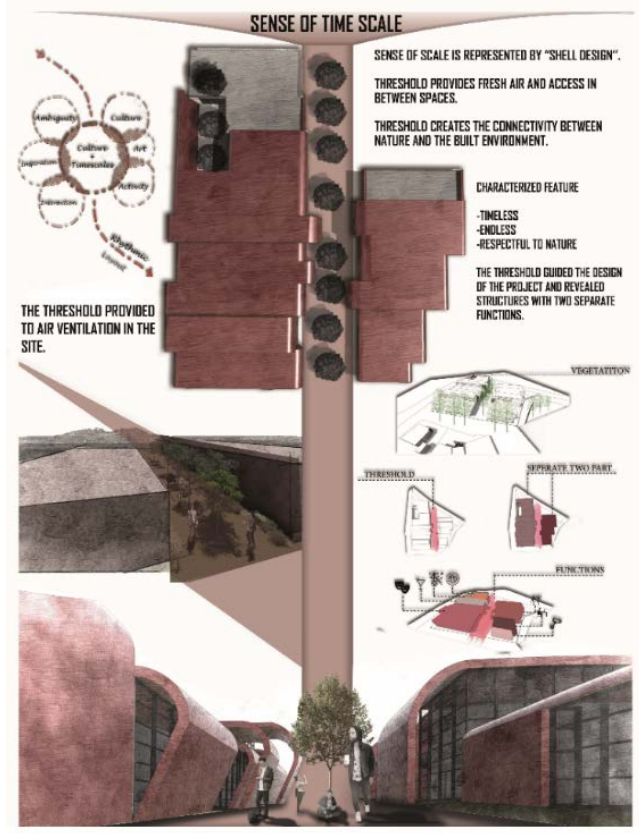

Fig1. Student project in which threshold taken in consideration as a physical separator.

In another student project; there is a blue zone. This blue zone seperates the functions into two main axis such as social and medical axis, divide building to private and public parts. Blue zone is a doorway for patient to heal with social areas, accomadation, meditation,yoga parts and natural walkway. With the blue zone project is divided into zones according to public, semi public and private, (fig 2).

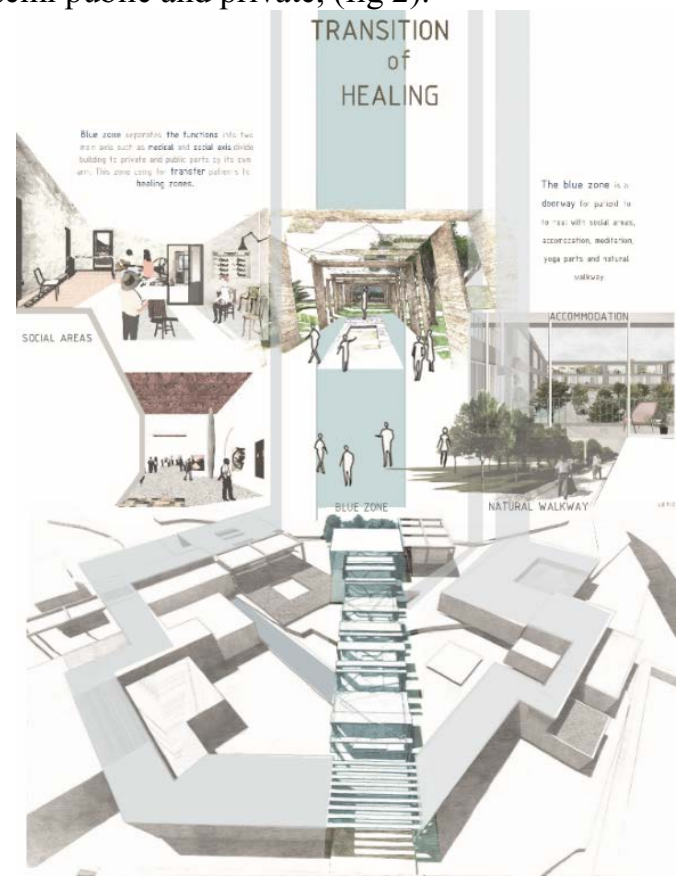

Fig 2. Student project in which threshold taken in consideration as a privacy seperator. 
The results of this study are interesting. As threshold has many meanings, almost every project take threshold in different perspectives. In the architectural design studio, many different thresholds come apart. In this study some projects of student that have different perspectives are explained. Ways of applying threshold is discussed in this paper. By this acknowledgement can be done for the ones who prefer to use threshold in their architectural design.

\section{References}

1. https://dictionary.cambridge.org/tr/

2. https://www.ldoceonline.com/

3. Walter Benjamin and Rolf Tiedemann, The Arcades Project (Cambridge, Mass: Belknap Press), 494, (1999).

4. Till Boettger, Threshold Spaces: Transitions in Architecture Analysis and Design Tools (Basel, Switzerland: Birkhäuser), 15-51, (2014).

5. Quentin Stevens, "Betwixt and Between: Building Thresholds, Liminality and Public Space," in Loose Space: Possibility and Diversity in Urban Life, ed. Karen A. Franck and Quentin Stevens (London; New York: Routledge), 73-92, (2007).

6. Land, R., Meyer, J.H.F. and Baillie, C., Editors' Preface: Threshold Concepts and Transformational Learning,in: Threshold Concepts and Transformational Learning, Land, R., Meyer, J.H.F. and Baillie, C., (eds), Sense Publishers, Rotterdam, pp. ix-xlii, (2010).

7. Catherine Dee in her book 'Form and Fabric in Architecture', Spon Press, London and New York, (2001). 